\title{
Cooperação Internacional para o Desenvolvimento e Educação: um estudo preliminar sobre os desafios e possibilidades a partir da experiência compartilhada entre Brasil e Timor-Leste
}

\author{
Maria Denise Guedes* \\ Vicente Paulino**
}

\begin{abstract}
Resumo
O presente artigo visa à sistematização dos resultados de estudos preliminares sobre os desafios e possibilidades de desenvolvimento de um trabalho de cooperação internacional compartilhada em Timor-Leste. Nesse sentido, partindo da problematização do papel da Cooperação Internacional para o Desenvolvimento nos países em desenvolvimento, tem-se como hipótese inicial que, após a restauração da independência, em 2002, e com a chegada das agências internacionais de cooperação, que aportaram em Timor-Leste com o objetivo de "ajudar" na construção do Estado-Nação, o maior desafio que o país vive é o enfrentamento da contradição entre, por um lado, atender às exigências das agências internacionais, capitaneadas pela Organização das Nações Unidas e pelo Banco Mundial, para colocar o Estado timorense e suas instituições nos trilhos da "globalização" e, por outro, defender e preservar sua identidade cultural. Portanto, com base em estudos de natureza bibliográfica, nos pressupostos teórico-metodológicos da dialética marxista e no pensamento de Paulo Freire, bem como na experiência vivida pelos autores por meio do Programa de Qualificação de Docentes e Ensino de Língua Portuguesa em Timor-Leste, conclui-se que o compromisso, a vontade política e o respeito pelas diferenças culturais entre os agentes envolvidos nas ações de cooperação são ingredientes necessários para superar os desafios e avançar na construção de uma relação de cooperação internacional compartilhada.
\end{abstract}

Palavras-chave: Cooperação Internacional. Internacionalização da Educação. Contexto Mundial.

\footnotetext{
* Doutora em Educação pela Universidade Federal de São Carlos (UFSCar). Professora do Departamento de Educação do Instituto de Biociências, Letras e Ciências Exatas da Universidade Estadual Paulista "Júlio de Mesquita Filho" (UNESP), Campus de São José do Rio Preto, SP.

*** Professor da Universidade Nacional Timor Lorosa'e (UNTL).
} 


\section{Introdução}

O tema de que tratamos no presente artigo é resultado de nossos estudos preliminares sobre os desafios e possibilidades de desenvolvimento de um trabalho de cooperação internacional em educação em Timor-Leste, de modo que atenda às demandas da educação contemporânea do país, sem perder de vista suas necessidades locais. Nossa reflexão, iniciada em reuniões de trabalho na Universidade Nacional Timor-Lorosa'e (UNTL), tem como ponto de partida as seguintes questões: quais são os desafios que Timor-Leste enfrenta, na atualidade, para assegurar o desenvolvimento, com qualidade, da educação no país? Quais são as possibilidades de construção de uma experiência de cooperação educacional compartilhada, entre Brasil e Timor-Leste, para o enfrentamento desses desafios?

Com base nessas questões, chegamos à hipótese inicial de que, após a restauração da independência, em 2002, e com a chegada das agências internacionais de cooperação, que aportaram no país com o objetivo de "ajudar" na construção do Estado-Nação da República Democrática de TimorLeste, após a ocupação indonésia, o maior desafio que o país vive é o enfrentamento da contradição entre, por um lado, atender às exigências das agências internacionais, capitaneadas pela Organização das Nações Unidas (ONU) e pelo Banco Mundial, para colocar o Estado timorense e suas instituições nos trilhos da "globalização", e, por outro, defender e preservar sua identidade cultural. Nessa perspectiva, consideramos que um caminho profícuo para avançarmos nessa construção seria o desenvolvimento de estudos sobre o papel da Cooperação Internacional para o Desenvolvimento nos chamados países em desenvolvimento, visando produzir pesquisas e estudos críticos que coloquem em evidência e problematizem essa contradição no âmbito da realidade histórico-social e educacional timorense.

Buscando compreender essa contradição entre a necessidade de preservação da identidade cultural do país e as exigências impostas por uma agenda capitalista global, proclamada mundialmente por organismos multilaterais que tomam para si a tarefa de traçar e determinar os caminhos a serem seguidos pelos chamados países em desenvolvimento, sistematizamos, neste artigo, os resultados de estudos preliminares sobre o papel da Cooperação Internacional para o Desenvolvimento nos chamados países em desenvolvimento, desde a sua origem até a atualidade. A partir dessa análise e da experiência compartilhada pelos autores, em 2014, por meio do Programa de Qualificação de Docentes e Ensino de Língua Portuguesa em Timor-Leste (PQLP), discorremos sobre o trabalho desenvolvido pela 
cooperação educacional brasileira na UNTL, descrevendo alguns exemplos das atividades desenvolvidas no âmbito do ensino, da pesquisa e da extensão.

Consideramos que é a prática social cotidiana que provoca, em nós, a necessidade de problematizar, de refletir sobre os fenômenos com os quais nos deparamos em nosso dia a dia. Portanto, em termos metodológicos, a experiência concreta com a realidade social e educacional timorense constitui o ponto de partida e também o ponto de chegada da nossa reflexão, pois, conforme observou Marx (1987, p. 16), a realidade concreta, inicialmente, aparece no pensamento como uma representação caótica da totalidade das relações sociais, "como resultado, não como ponto de partida, ainda que seja o ponto de partida efetivo e, portanto, o ponto de partida também da intuição e da representação". Para esse autor, uma investigação científica que pretenda desvelar a realidade concreta de determinado fenômeno social, em sua essência, deve proceder do abstrato para apropriar-se do concreto e, em seguida, fazer o caminho de volta, para então reproduzi-la como concreto pensado, isto é, elaborado pelo pensamento. Isso significa que somente por meio de uma análise mais precisa, mediada pela teoria e que permita a decomposição do fenômeno observado em categorias cada vez mais simples, podemos compreender a sua essência.

Nessa perspectiva, a análise científica da realidade concreta social, educacional e cultural de Timor-Leste pressupõe, para que possamos ir além da sua aparência, o desvelamento da contradição que o país enfrenta, a qual, conforme afirmamos acima, constitui-se da necessidade de atender às determinações de um projeto político hegemônico - a assim chamada globalização - financiado pelo capital e executado por organismos e agências multilaterais ou bilaterais que o representam, e, ao mesmo tempo, atender à necessidade de preservar sua identidade cultural. Dessa forma, tal contradição só pode ser compreendida em sua essência pela mediação da teoria, ou seja, por meio da análise científica que procede do abstrato, que é o concreto idealizado no pensamento.

Segundo a dialética marxista, analisar esse fenômeno particular em sua essência pressupõe que ele seja compreendido a partir da totalidade das relações sociais capitalistas e do papel institucional que a Cooperação Internacional para o Desenvolvimento assume, historicamente, no interior dessas relações. Esse caminho metodológico pode contribuir para compreendermos as leis, universais e particulares, que regulam o movimento contraditório da realidade concreta que o país vive na atualidade, cuja expressão fenomênica revela apenas a sua aparência. Conforme nos lembra Kosik 
(1995), compreender as leis que regulam o movimento do fenômeno, em sua essência, é a tarefa da ciência.

Diante do exposto, a categoria contradição é fundamental para a análise da problemática que pretendemos investigar, pois, segundo a dialética materialista e histórica, a contradição regula o movimento da realidade e a ela é inerente. Tomá-la como categoria analítica contribuirá para a compreensão do conceito de identidade em sentido universal e da identidade cultural timorense em particular, uma vez que a contradição é a lei que dá unidade aos contrários e faz parte da essência do fenômeno, revela sua identidade. De acordo com Mao Tse-tung (1975 apud BOGO, 2010, p. 27-28), os conceitos de contradição e identidade, “[...] em determinadas condições, por um lado, eles se opõem um ao outro, por outro lado, estão ligados mutuamente, impregnam-se reciprocamente, interpenetramse e dependem um do outro [...].

Bogo (2010, p. 27), corroborando o acima exposto, esclarece que “a questão da identidade está primeiramente ligada à categoria dialética "unidade dos contrários"". Ou seja, "uma coisa não pode existir sem que haja seu oposto, e somente pode se chegar à verdade, quando se conseguir encontrar o seu contrário". Para o autor, vida e morte, senhor e escravo, burguesia e proletariado, por exemplo, são contradições que se enfrentam e que, ao mesmo tempo, dependem uma da outra para existir com suas características particulares. Portanto, consideramos que só podemos compreender o significado da categoria identidade, em suas características particulares, ao analisá-la a partir do seu oposto, que é a contradição. É nesse sentido que elegemos a contradição como categoria analítica para compreender a identidade social, cultural e educacional timorense, em suas características particulares, a partir do movimento contraditório da realidade que o país enfrenta no atual contexto das relações sociais capitalistas.

A partir dos fundamentos teórico-metodológicos acima explicitados, reportamo-nos também ao pensamento de Paulo Freire (1978), por entendermos que contribui para a análise do nosso objeto de pesquisa. Em suas Cartas à Guiné Bissau, o autor faz-nos lembrar que "[...] não há real ajuda entre classes dominantes e classes dominadas nem entre as 'sociedades imperiais' e as chamadas sociedades dependentes, de fato, dominadas, na compreensão de cujas relações não se pode prescindir da análise de classe" (FREIRE, 1978, p. 11). As reflexões, especialmente na obra citada, vêm ao encontro dos nossos pressupostos e os complementam, pois entendemos que, para compreender as atividades da Cooperação Internacional para o Desenvolvimento em um país ou nação em processo de reconstrução de suas instituições, como é o caso de Timor-leste, não partimos do zero, “[...] mas de suas fontes 
culturais e históricas, de algo de bem seu, da alma mesma de seu povo, que a violência colonialista não pôde matar" (FREIRE, 1978, p. 11). Embora Freire se refira a sua experiência em Guiné-Bissau, consideramos que suas análises também contribuem para nossa reflexão sobre o contexto históricosocial timorense.

\section{Timor-Leste: síntese das características geográficas, históricas, linguísticas e culturais}

Em termos de localização geográfica, Timor-Leste corresponde à metade de uma pequena ilha localizada no sudeste da Ásia e suas fronteiras o situam entre o continente Asiático e a Oceania. De um lado, faz divisa terrestre com a Indonésia e, de outro, por mar, com a Austrália. Essa área do Oceano Pacífico é conhecida como Anel de Fogo, devido à ocorrência intensa de terremotos. É uma das ilhas que compõem o arquipélago indonésio: ao norte é limitada pelo mar de Wetar; ao Sul, banhada pelo mar de Timor, que a separa da Austrália; e a Noroeste, pelo mar de Savu, que a põe em contato com as ilhas de Sumba, Flores e Solor.

Dias (2015), em pesquisa recente sobre a questão linguística em Timor-Leste, explica que a necessidade da população de se comunicar em várias línguas, em função das atividades comerciais entre os primeiros habitantes da ilha, de origem austronésia, e os diferentes povos que por ali passaram - chineses, indianos, indonésios, árabes, papuas e, posteriormente, também portugueses, holandeses, japoneses e australianos -, fez de Timor-Leste um país multiétnico, multicultural e multilíngue.

Segundo Thomaz (2008), no período anterior à colonização portuguesa, a ilha dividia-se em dois reinos: dos Belos, que corresponde à parte oriental, e do Servião, localizado na parte ocidental. Assim explica o autor:

País dos Belos: assim se chamava outrora a metade oriental de Timor. A outra é geralmente designada nos textos portugueses pelo nome de Província do Servião. Embora seus limites não coincidissem exactamente com o que é hoje a fronteira entre Timor-Leste e a província indonésia de Nusa Tenggara Timur, a divisão da ilha em duas não resulta dos azares da história colonial, pois é-lhe anterior. Parece, aliás, haver na região uma tendência para que os grupos etnolinguísticos não coincidam com as ilhas: na parte ocidental da ilha de Sumbawa falam-se línguas congéneres das de Lombok e Bali, ao passo que em Bimam, sua metade oriental, os falares se aparentam antes aos Sumba e Mangagarai, no 
oeste das Flores; mas já no extremo leste desta derradeira ilha se falam línguas do grupo das de Timor [...]. (THOMAZ, 2008, p. 15).

O pesquisador timorense Francisco Martins (2010) relata que, atualmente, existem no país 35 grupos étnicos e linguísticos que se comunicam em suas próprias línguas nativas, sendo as principais: tétum, fataluco, macasae, bumac, quemac, mambae, tocodede, galolen, idate, habo, maclero, dagada e waimu'a.

O tétum é a língua mais falada na capital Díli. Considerada a língua franca, em 2002, a língua foi elevada à categoria de língua oficial, ao lado da língua portuguesa, pela Constituição do país. A segunda língua mais falada é a bahasa indonésia, herança deixada após 24 anos de ocupação do território pelos indonésios, e que hoje é considerada como língua de trabalho, ao lado do inglês.

Como podemos observar, a pluralidade linguística constitui-se em uma das marcas da cultura timorense. Tal característica não deve ser menosprezada, se pretendemos colaborar para o desenvolvimento da educação no país. O fato é que todas essas línguas circulam no interior das escolas, desde a educação básica ao ensino superior, ao lado da língua portuguesa, que é considerada a língua de ensino pela legislação educacional. Nesse sentido, o desafio de aprender a falar e escrever em língua portuguesa é, também, uma das contradições vividas pelos nativos daquele país, cuja compreensão se faz necessária para o entendimento de sua identidade cultural.

De acordo com Salgado (2006), historicamente, Timor-Leste foi formado por pequenos reinos, organizados e divididos por regiões administrativas denominadas sucos, que, por sua vez, constituíamse de um conjunto de aldeias. Administrativamente, esses reinos eram governados por liurais, equivalentes a reis ou chefes de reino, reconhecidos e respeitados como autoridade política e religiosa da comunidade e "reverenciado[s] como o protetor e senhor dos corações e mentes" (SALGADO, 2006, p. 4). Essa divisão político-administrativa em sucos e aldeias foi mantida, assim como a autoridade do liurai se mantém preservada. Atualmente, o país está organizado em 13 distritos, 67 postos administrativos ou subdistritos, 498 sucos e 2.336 aldeias, nos quais o liurai se mantém no topo da hierarquia e continua reverenciado e respeitado como o senhor dos corações e mentes, inclusive pelos representantes políticos que passaram a governar o Estado Democrático de Direito, em construção desde 2002.

Esses traços singulares da cultura timorense, herdados dos seus antepassados, tais como o respeito à hierarquia e à diversidade linguística, entre outros, convivem com diferentes formas de pensar e sentir a vida, trazidas pelo malae ${ }^{1}$, e com a ideologia da globalização, trazida pelas agências 
internacionais de cooperação desde que o país iniciou o processo de (re)construção do Estado nacional. Esse caldo cultural que, paulatinamente, foi sendo absorvido pelo povo maubere ${ }^{2}$ e incorporado aos costumes locais, sobretudo daqueles que vivem na capital do país, constitui-se em um dos aspectos que compõem o movimento contraditório das relações sociais do país na atualidade.

Outro aspecto importante que marca a identidade cultural timorense é sua história de luta e resistência contra sucessivas estratégias de domínio do seu território. Silva (2012) lembra que toda essa história foi acompanhada de violência, destruição e mortes, ainda hoje sentidas e lembradas pela geração que as vivenciou. Conforme afirma Mattoso (2012), a resistência timorense tem como pressuposto a luta pela dignidade. Dignidade e liberdade, portanto, são os ingredientes que alimentam a resistência timorense aos invasores e asseguram sua identidade. Resistir ou morrer, essa é a máxima vivida, sentida, ensinada e cantada em versos por suas sucessivas gerações. É com base nesse lema que os mais velhos educam seus filhos. Trata-se, do nosso ponto de vista, de um princípio educativo fundamental na luta pela defesa da identidade cultural desse povo. A citação abaixo, retirada dos versos de uma canção escrita por um timorense, sintetiza esse princípio educativo:

Resistir ou morrer é o meu viver. Numa luta desigual eu quero vencer. Não quero que um dia me venham dizer que o Timor já não é o meu Timor. Combatendo as injustiças do opressor, todos lutam desde a mais tenra idade. Sabendo que o Senhor está ao meu favor, a minha morte é mais um passo para a liberdade. Por mais corpos que eu vejo pelo chão, por mais forte que seja o invasor, os meus gritos jamais se calarão. Até a morte lutarei por ti, Timor $[\ldots]^{3}$.

Após 24 anos de ocupação indonésia, foi com esse espírito de resistência aos invasores, associado ao desejo de liberdade e à defesa de sua identidade cultural, que, em 30 de agosto de 1999, a população timorense, por meio de um referendo, depositou nas urnas o desejo e a esperança de tornarse um país definitivamente independente, agora com apoio da ONU, que assumiu a administração transitória do país de 1999 até 2002. Assim, em maio de 2002, Timor-Leste conquistou a restauração de sua independência, que já havia sido proclamada, unilateralmente, em 1975. Entretanto, a conquista da independência política foi apenas o início de uma nova e longa batalha, que se estende até hoje, para assegurar o desenvolvimento do Estado-Nação e, ao mesmo tempo, preservar sua identidade cultural. Essa, como já dissemos, é a contradição que o país enfrenta na atualidade; compreendê-la é também um desafio, para nós, se quisermos superar os limites impostos pela realidade ao trabalho da cooperação brasileira. 
A referida assunção da administração do país pela ONU instituiu, por meio da Resolução $\mathrm{n}^{0}$ 1.272, do Conselho de Segurança, a Administração Transitória das Nações Unidas em Timor-Leste (UNTAET). Segundo Neves (2007), foi a partir desse período que a cooperação internacional começou a chegar a Timor-Leste, primeiramente em forma de ajuda emergencial e humanitária, depois visando à reconstrução e ao desenvolvimento e, por fim, à cooperação de longo prazo. Conforme esclarece o autor:

Como em outros países do Terceiro Mundo que recebem recursos internacionais, o dinheiro vem acompanhado pelas instituições multilaterais, pelas Instituições Financeiras Internacionais, pelas agências da ONU, pelas organizações não-governamentais (ONG) ocidentais, pelas agências internacionais de desenvolvimento (norte-americana - USAID, australiana AusAID, japonesa - JICA), pelos funcionários e consultores internacionais, pelos empresários estrangeiros e pelos equipamentos importados do exterior. Eles trouxeram até mesmo hotéis flutuantes para acomodar os trabalhadores estrangeiros. (NEVES, 2007, p. 99).

Ou seja, desde o início da década de 2000, Timor-Leste contou, financeira e tecnicamente, com a ajuda externa por meio da Cooperação Internacional para o Desenvolvimento. Com ela aportaram no país agências de cooperação multi e bilateral com a missão de ajudar na reconstrução do Estado-Nação, assim como na elaboração e organização de suas leis e instituições. Tal ajuda, à primeira vista, pode sugerir ação auspiciosa, por ser constituída pela solidariedade dos países estrangeiros no sentido de contribuir para o desenvolvimento da nação timorense. Entretanto, um olhar mais atento permite perceber que o país passou a enfrentar novos problemas com a chegada das agências de cooperação internacional, pois com elas chegaram também diferentes tipos de pessoas, com concepções de mundo e experiências técnicas e profissionais adquiridas em seus países de origem, portanto, muito distintas da cultura e visão de mundo da população atendida. Nesse sentido, constata-se que nem sempre a visão dos "especialistas" estrangeiros reflete as necessidades daqueles que recebem a ajuda.

Simião e Silva (2007, p. 15-16), ao analisarem as práticas da cooperação internacional em Timor-Leste, afirmam que, mais do que uma ajuda externa, "mais do que um simples ato de boa vontade", elas representam um instrumento político, tanto entre os países doadores como entre os beneficiários que recebem a assistência negociada. Por meio dela, argumentam os autores, "[...] países intervêm no destino de outros, fazendo uso, na maioria dos casos, de recursos públicos. Em tempos de governança global, as políticas de cooperação são, pois, problemas de todos nós. Como tais, devem ser compreendidas e analisadas criticamente" (SIMIÃO; SILVA, 2007, p. 16). 


\section{Cooperação Internacional para o Desenvolvimento: origem, desenvolvimento histórico e função}

A partir dos estudos realizados por Milani (2014), Iglesias Puente (2010), Guedes (2006), Fiori (2002), Frigotto (1995), Gentili (1996) e Silva (2003), apresentamos uma síntese dos trabalhos sobre a origem, o desenvolvimento histórico e a função institucional e "educadora" da Cooperação Internacional para o Desenvolvimento nos países da periferia do sistema capitalista, como é o caso do Brasil e de TimorLeste.

Segundo Milani (2014), a origem da Cooperação Internacional para o Desenvolvimento tem como marco histórico o contexto da II Guerra Mundial e da Guerra Fria. No entanto, o autor observa que diferentes concepções e práticas de cooperação internacional já existiram em outros períodos, as quais eram aplicadas pelos Estados Unidos por meio de programas pontuais de ajuda humanitária, assim como projetos de assistência técnica e de apoio ao desenvolvimento das colônias pelos Estados europeus. A partir de 1945, esse conjunto de experiências temporárias, movidas por interesses políticos, diplomáticos e humanitários, institucionalizou-se como um conjunto de normas e práticas de atores e agendas mais definido e organizado, que passaram a orientar o modo de atuação dos Estados no âmbito das relações internacionais entre os países centrais e periféricos do sistema capitalista. Nesse contexto, as disputas econômicas, políticas e ideológicas entre países capitalistas e socialistas foram fatores determinantes que marcaram o processo de institucionalização da Cooperação Internacional para o Desenvolvimento. Além desses fatores, a reconstrução da Europa no pós-guerra e o processo de descolonização na África, Ásia, no Caribe e no Pacífico, nos anos de 1950 a 1970, bem como a emergência do modelo econômico nacional-desenvolvimentista também foram fatores determinantes que ajudam a compreender sua consolidação (MILANI, 2014).

Nos primeiros anos de institucionalização da Cooperação Internacional para o Desenvolvimento, foram estabelecidas organizações internacionais multilaterais, como a Organização de Cooperação Econômica Europeia (OECE) e agências da ONU: a Organização das Nações Unidas para a Educação, a Ciência e a Cultura (UNESCO); a Organização Mundial da Saúde (OMS); o Fundo das Nações Unidas para a Infância (UNICEF); e o Fundo das Nações Unidas para Alimentação e Agricultura (FAO). Além dessas agências multilaterais, “os principais países doadores criaram suas próprias agências bilaterais de cooperação para o desenvolvimento” (MILANI, 2014, p. 34). Nesse 
cenário, as agências bilaterais ficaram responsáveis pela assistência técnica e orçamentária aos países em desenvolvimento, enquanto às agências multilaterais ficaram reservadas as funções de implementação, gerenciamento e apoio de projetos nos países beneficiários.

De acordo com os estudos realizados por Iglesias Puente (2010), o desenvolvimento da Cooperação Internacional para o Desenvolvimento pode ser classificado em quatro fases: 1) 1950 e 1960 - "fase das lacunas"; 2) 1970 - "fase da dimensão social"; 3) 1980 - "fase do ajuste estrutural"; 4) 1990 em diante - "fase do Após Guerra Fria e da Boa Governança".

Na primeira fase (1950-1960), a atuação da Cooperação Internacional para o Desenvolvimento estava voltada para o investimento de capital nas "economias subdesenvolvidas", as quais dispunham de matéria-prima e mão de obra, mas faltava-lhes, segundo os países doadores, investimento de capital para o seu desenvolvimento econômico e social (IGLESIAS PUENTE, 2010, p. 42). Nesse período, a teoria keynesiana - que tinha como princípios o planejamento e a intervenção do Estado na economia sustentava as teses desenvolvimentistas e de modernização da Cooperação Internacional para o Desenvolvimento. Nesse contexto, com base nos pressupostos da ideologia desenvolvimentista, propagada por meio das agências multilaterais e bilaterais de cooperação internacional, os países passaram a ser classificados por essas agências como desenvolvidos e subdesenvolvidos, a partir de indicadores de medidas econômicas, de desenvolvimento tecnológico e de infraestrutura física.

Na década de 1970, classificada por Iglesias Puente (2010) como a fase da dimensão social da Cooperação Internacional para o Desenvolvimento, os analistas da assistência para o desenvolvimento, com base nos indicadores supracitados, passaram a apontar as falhas no modelo pautado em investimento de capital. Por um lado, do ponto de vista dos países "recipientários", os recursos recebidos eram insuficientes e, por outro lado, na visão de alguns países doadores, esses recursos eram mal aplicados ou aproveitados. A análise realizada pelo autor sugere que, para os analistas das cooperações, o investimento de capital não atingiu seu objetivo, que era prover de recursos os países em desenvolvimento para que alcançassem o equilíbrio econômico e o desenvolvimento autossustentável. Nesse contexto, a dimensão social do desenvolvimento e a necessidade de promover crescimento com redistribuição de renda começou a se impor e, "pela primeira vez, a luta contra a pobreza, a situação marginal da mulher e os indicadores sociais básicos ganham relevo nos esforços analíticos da ajuda externa para o desenvolvimento" (IGLESIAS PUENTE, 2010, p. 44).

De nossa perspectiva, a revisão dos resultados anteriores da atuação da Cooperação Internacional nos países em desenvolvimento é determinada pelo acirramento das contradições da 
sociedade capitalista, que tem como fator essencial o antagonismo entre capital e trabalho. A expressão fenomênica dessa contradição se manifesta, a partir de 1970, por meio de uma profunda crise estrutural, de ordem econômica, energética, ambiental, política e social que afetou os países do Norte e do Sul, do Leste e do Oeste, do Centro e da Periferia. Nesse contexto, por um lado, os países doadores começaram a exigir que os países beneficiários assumissem maiores responsabilidades pelo desenvolvimento de suas nações e a acenar para mudanças necessárias nas economias nacionais destes. Por outro lado, economistas, sociólogos e educadores, entre os quais, o educador brasileiro Paulo Freire (1978), passaram a criticar as ações da Cooperação Internacional nos países em desenvolvimento e a reivindicar maior participação popular nas decisões das políticas públicas entre os atores nacionais.

Desde então, visando ocultar as contradições expostas pela crise, as agências internacionais de cooperação para o desenvolvimento se apropriam do vocabulário dos seus críticos e as incorporam em seus manuais. Nesse sentido, de acordo com Milani (2014, p. 38):

[...] participar tornou-se elogio frequente nos manuais das agências internacionais de cooperação para o desenvolvimento. A participação social, também conhecida como participação dos cidadãos, participação popular, participação democrática, participação comunitária, entre os muitos termos utilizados para referir-se à prática de inclusão dos cidadãos e das organizações da sociedade civil (OSC) no processo decisório de algumas políticas públicas, foi erigida em princípio político. Fomentar a participação dos diferentes atores sociais em sentido abrangente e criar uma rede que informe, elabore, implemente e avalie as decisões políticas converteu-se em paradigma de inúmeros projetos de desenvolvimento local (auto) qualificados de inovadores e de políticas públicas locais (auto) consideradas progressistas.

Nos anos 1980, fase classificada por Iglesias Puente (2010) como a "fase do ajuste estrutural", nos receituários das agências de Cooperação Internacional para o Desenvolvimento passou a constar estratégias para enfrentamento da crise de endividamento nos países do Sul, entre as quais programas de ajuste estrutural que tinham como objetivo impor condicionalidades aos países em desenvolvimento para receberem ajuda financeira dos países doadores. Assim esses países beneficiários foram submetidos:

[...] a pacotes de austeridade fiscal, financeira e econômica que seguiam a receita ideológica e teórica do Estado mínimo, bem como os parâmetros políticos do Consenso de Washington - ou seja, redução e "racionalização" do setor público, implementação de políticas macroeconômicas segundo os 
preceitos do Fundo Monetário Internacional (FMI) e do Banco Mundial, abertura das economias nacionais ao comércio internacional e abandono dos modelos nacional-desenvolvimentistas. A presença de governos conservadores nos Estados Unidos (Ronald Reagan) e no Reino Unido (Margareth Thatcher) somente facilitou a legitimação e a posterior difusão de tais preceitos no mundo em desenvolvimento. (MILANI, 2014, p. 42).

O Consenso de Washington, cujo objetivo consistiu em definir o pacote de reformas a serem realizadas nos países periféricos do sistema capitalista, foi instituído em novembro de 1989, em Washington, quando foi realizada uma reunião entre os organismos de financiamento internacional Fundo Monetário Internacional (FMI), Banco Interamericano de Desenvolvimento (BID) e Banco Mundial -, funcionários do governo americano e economistas dos países em desenvolvimento. Tal encontro condensava e traduzia as ideias neoliberais, cuja hegemonia já imperava nos países centrais do capitalismo, e determinou as principais reformas estruturais, ou institucionais, a serem seguidas pelos países da periferia capitalista: 1) desregulação dos mercados financeiro e do trabalho; 2) privatização das empresas e dos serviços públicos; 3) abertura comercial; 4) garantia do direito de propriedade dos estrangeiros, sobretudo nas zonas de fronteira tecnológica e dos novos serviços (GUEDES, 2006).

Nessa perspectiva, o Consenso de Washington sintetizou as condicionalidades, impostas pelos organismos internacionais e pelo sistema bancário privado, para a renegociação das dívidas externas dos países em desenvolvimento e para a readmissão destes no sistema financeiro internacional. Essa lógica mercantilista tinha como pressuposto que, depois da estabilização financeira e das reformas, haveria, inevitavelmente, uma retomada dos investimentos e do crescimento, cuja liderança estaria nas mãos do capital privado. Ou seja, constituiu-se num "adeus" às teses keynesianas, pois era preciso livrar a economia das interferências do Estado e liberar o comércio e os preços para que os países alcançassem um desenvolvimento sustentável e as desigualdades sociais e nacionais fossem reduzidas espontaneamente (FIORI, 2002). Nessa nova fase da atuação da Cooperação Internacional para o Desenvolvimento, em 1980, o Banco Mundial e o FMI inauguraram a modalidade de empréstimo de ajuste estrutural aos países em desenvolvimento (IGLESIAS PUENTE, 2010).

A partir de 1990, as agências multilaterais e bilaterais de cooperação internacional passaram a difundir os pressupostos da nova ordem econômica mundial por meio de conferências internacionais, com o objetivo de impor a reforma política a ser seguida pelos Estados nacionais, fundamentalmente, os países periféricos do sistema capitalista. Esse período inaugurou a quarta fase de da Cooperação 

possibilidades a partir da experiência compartilhada entre Brasil e Timor-Leste

Internacional para o Desenvolvimento, denominada por Iglesias Puente (2010, p. 47) de "fase do Após Guerra Fria e da Boa Governança”, que teve como marcos históricos a queda do muro de Berlim e o final da Guerra Fria. Nesse período, do ponto de vista econômico, os principais países doadores promoveram, dentre as estratégias que visavam à superação da crise internacional instalada, a redução dos montantes da Ajuda Oficial para o Desenvolvimento (AOD). As agências multilaterais internacionais, representantes dos principais países doadores, justificavam a redução de custos alegando a falta de comprometimento, dos países em desenvolvimento, com a realização das reformas propostas, o desvio da finalidade da ajuda externa e a corrupção endêmica. Nesse momento, teve início a propagação ideológica do paradigma da "boa governança" como condicionalidade para os países em desenvolvimento continuarem recebendo ajuda. Na prática, conforme explica o autor:

[...] o paradigma da boa governança sacramenta a tendência mais recente, entre os PD (Países Desenvolvidos), de atribuir a responsabilidade pelo processo de desenvolvimento aos próprios PED (Países em Desenvolvimento), na assunção de que os fluxos internacionais privados de capitais e de comércio devem assumir o primeiro plano dos esforços pelo desenvolvimento. Nesse pressuposto a AOD deve atuar apenas como catalisadora desses fluxos, ao mesmo tempo em que promove a boa governança e as condições para que o capital privado encontre campo fértil. O corolário disso é a diminuição da cooperação internacional nos setores produtivos (supostamente a cargo dos investidores externos) e sua concentração em setores que o mercado não atua: saúde, educação, saneamento básico, entre outros. (IGLESIAS PUENTE, 2010, p. 4849).

No âmbito da educação, em 1990, a Conferência Mundial sobre Educação para Todos, em Jomtien, na Tailândia, patrocinada por UNESCO, UNICEF, Programa das Nações Unidas para o Desenvolvimento (PNUD) e Banco Mundial, inaugurou essa nova fase da Cooperação Internacional para o Desenvolvimento, cuja função “educadora” consistia em proclamar a educação para paz e alívio da pobreza como estratégia para minimizar os efeitos da crise e ocultar as contradições dela decorrentes. A partir dessa conferência, essas agências começaram a divulgar as diretrizes políticas e pedagógicas que passariam a orientar as reformas do Estado e da Educação no âmbito da nova ordem política e econômica do capitalismo mundial (GUEDES, 2006).

No Brasil, várias pesquisas foram desenvolvidas com o objetivo de analisar a reforma da educação brasileira, iniciada na década de 1990 e capitaneada por essas agências de cooperação internacional. Tais pesquisas analisam a realidade educacional brasileira e seu movimento contraditório no contexto das políticas neoliberais, as quais têm a desigualdade social como princípio fundamental 
para assegurar a liberdade do mercado e estimular a livre concorrência entre o capital privado, as nações e os indivíduos, e promover a inserção dos países periféricos do sistema e de seus cidadãos na assim chamada "era da globalização". (FRIGOTTO, 1995; GENTILI, 1996; FIORI, 2002; GUEDES, 2006; SILVA, 2003)

Maria Abádia da Silva (2003), por exemplo, em sua pesquisa sobre o projeto político do Banco Mundial, analisa os mecanismos de intervenção do Banco e suas formas de cooptação na estrutura organizacional e institucional, bem como no funcionamento da escola pública brasileira. Entre outros aspectos, essa pesquisadora observa o seguinte:

Não é apenas a presença das missões e dos técnicos do Banco Mundial que nos preocupa, algo que vem sendo praticado desde 1964, quando foram assinados os Acordos MEC-USAID, entregando a reorganização da educação brasileira aos técnicos da Agency for International Development [AID] (Romanelli, 2003, p. 213), mas a receptividade que este pensamento encontra nos técnicos brasileiros e que se materializa na criação de uma estrutura paralela ao MEC para fiscalizar, avaliar e pressionar, com a anuência do governo federal. A presença e a atuação desses técnicos foi exemplar na década de 1990, pela sua capacidade de servir-se da estrutura organizacional para canalizar seus objetivos, ideologias, estratégias e concepção de educação. (SILVA, 2003, p. 288).

As pesquisas realizadas sobre os resultados da presença e da influência que essas agências internacionais de cooperação exerceram nas políticas educacionais do Brasil e demais países da América Latina geraram vasta produção de conhecimento científico que também pode contribuir para os estudos sobre a presença dessas agências e seus resultados para a educação em Timor-Leste, pois, desde a restauração da independência do país, em 2002, essas agências nele aportaram com o objetivo, aparentemente auspicioso, de reconstruir o Estado e a educação do país.

\section{Brasil e Timor-Leste: algumas considerações sobre os desafios e possibilidades na construção de uma experiência de cooperação internacional compartilhada nos últimos 10 anos}

As ações da Cooperação Brasileira em Timor-Leste têm como pressuposto os princípios da chamada Cooperação Sul-Sul. Segundo Campos (2007), a modalidade de Cooperação Sul-Sul teve início na década de 1970, com o advento das discussões sobre a Nova Ordem Econômica Internacional 

possibilidades a partir da experiência compartilhada entre Brasil e Timor-Leste

(NIEO). Nesse momento, os países do Sul passaram a criticar a concepção de "ajuda externa" concebida, ao final da Segunda Guerra Mundial, pelos países desenvolvidos, conforme observado anteriormente. Desse modo, em 1978, na Conferência das Nações Unidas sobre Cooperação Técnica entre Países em Desenvolvimento, realizada em Buenos Aires, capital da Argentina - conferência esta que contou com a participação de 138 países -, a modalidade de Cooperação Sul-Sul foi institucionalizada. De acordo com o autor:

Mais do que uma modalidade de ajuda externa, a CTPD representa, portanto, um movimento concertado de países com estratégias de desenvolvimento nacional e internacional compatíveis com suas necessidades e condições conjunturais. Assim, se nos anos de 1970 os países estavam determinados a buscar auto-suficiência nacional e coletiva com o fim maior de promover uma nova ordem econômica internacional, já no século XXI, a CTPD tem sido definida como uma alternativa para neutralizar, ou pelo menos reduzir, as forças negativas do processo de globalização. A CTPD tem recebido outras denominações tais como "Cooperação Sul-Sul", ou ainda "Cooperação Horizontal”. (CAMPOS, 2007, p. 346)

De acordo com a Agência Brasileira de Cooperação do Ministério das Relações Exteriores (BRASIL, 2013, p. 13), a Cooperação Técnica Sul-Sul brasileira “[...] não é um meio para a transferência mecânica de conhecimentos e tampouco para transplantar práticas exógenas ao país parceiro sem atenção ao contexto social". Ela visa ao "[...] intercâmbio horizontal de conhecimentos e experiências originados nos países em desenvolvimento cooperantes” (BRASIL, 2013, p. 13).

O Acordo de Cooperação Educacional entre o Governo da República Federativa do Brasil e o Governo da República Democrática de Timor-Leste foi celebrado no dia 20 de maio de 2002, dia da restauração da independência de Timor-Leste. No artigo I desse acordo, podemos verificar a explicitação dos princípios da Cooperação Sul-Sul: "As Partes Contratantes comprometem-se a desenvolver a cooperação entre os dois países no âmbito da educação, de modo a contribuir para a melhoria da qualidade e eficácia da educação em seus países” (BRASIL, 2004a). O artigo III desse acordo estabelece como objetivos:

a) o fortalecimento da cooperação educacional em todos os níveis e modalidades de ensino; b) a formação e o aperfeiçoamento de docentes, pesquisadores, administradores educacionais, técnicos e outros especialistas em todos os níveis e modalidades de ensino; c) o intercâmbio de informações e experiências educacionais bem sucedidas em ambos os países; d) o incremento da cooperação interuniversitária e da produção científica. (BRASIL, 2004a). 
Com base nesse acordo, em 2003, o Brasil enviou para Timor-Leste uma equipe composta por seis professores brasileiros para realizarem a primeira Missão de Especialistas Brasileiros em Educação (MEBE), que tinha como objetivo prestar serviços técnicos de cooperação educacional (BORMANN; SILVEIRA, 2007). Na ocasião, essa equipe teve como tarefa prestar assessoria no desenvolvimento e na implantação do Plano de Desenvolvimento do Currículo Nacional, na redação da Lei de Bases da Educação Nacional e na formulação de políticas para a formação de professores em Língua Portuguesa (BORMANN; SILVEIRA, 2007). Essa equipe de professores brasileiros foi responsável por preparar o caminho para o que viria a seguir, ou seja, o desenvolvimento da educação escolar timorense orientada por uma legislação, por um currículo e pela formação de professores em Língua Portuguesa, a qual tinha acabado de se tornar oficial pelo texto constitucional da República Democrática de Timor-Leste (RDTL), ao lado da sua língua nativa, o tétum. A partir dessa experiência, a equipe de professores brasileiros retornou ao Brasil com novas demandas, apreendidas em contato com a realidade local.

Em continuidade ao cumprimento do acordo celebrado entre o governo brasileiro e o governo timorense, em 2004, o então presidente, Luiz Inácio Lula da Silva, instituiu, por meio do Decreto $\mathrm{n}^{\circ}$ 5.274, de 18 de novembro de 2004 (BRASIL, 2004b), o Programa de Qualificação Docente e Ensino de Língua Portuguesa (PQLP). Trata-se de um programa fomentado pela Coordenação de Aperfeiçoamento de Pessoal de Nível Superior (CAPES) em parceria com o Ministério das Relações Exteriores (MRE), cuja Coordenação Acadêmica está sob a responsabilidade da Universidade Federal de Santa Catarina (UFSC), desde 2009. O PQLP tem como objetivos contribuir para a formação inicial e continuada de professores timorenses, para o ensino da Língua Portuguesa e para o apoio ao ensino superior. Desde então, o governo brasileiro passou a enviar anualmente uma equipe de 50 professores brasileiros, formados em diferentes áreas do conhecimento, para desenvolverem ações de formação inicial e continuada de professores, desde a educação básica até o ensino superior.

Do ponto de vista organizacional, o PQLP é constituído em Timor-Leste por um grupo de até 50 professores, designados, de acordo com o edital de seleção da CAPES, como estagiários docentes. Entre os estagiários docentes, seis compõem uma equipe de articuladores pedagógicos. Essa equipe fica responsável pela coordenação, supervisão, formação contínua e avaliação dos professores brasileiros. Além disso, os articuladores pedagógicos mediam as relações entre os professores brasileiros e os professores das instituições educacionais timorenses.

Na educação superior, o PQLP, desde o seu início em 2005, vem atuando em diferentes frentes, em conformidade com as necessidades demandadas pelos gestores timorenses. Nesse sentido, 
desenvolve atividades de apoio ao ensino, à pesquisa, à extensão e à gestão. Nesse nível de ensino são desenvolvidas atividades em regime de codocência, uma vez que o PQLP tem por princípio o desenvolvimento de atividades compartilhadas entre os professores brasileiros e timorenses. Essas atividades envolvem a elaboração de planos de aulas, elaboração e revisão em Língua Portuguesa de material didático e de programas para as disciplinas dos cursos de graduação, quando solicitados pelo departamento de ensino. Além de realizar essas atividades, os professores brasileiros dividem o espaço da sala de aula com os professores timorenses e, muitas vezes, assumem as aulas, visando suprir a falta de professores timorenses em determinadas disciplinas.

No âmbito da pesquisa, o PQLP desenvolve atividades de apoio realizadas a partir da constituição de grupos de estudo e de pesquisa sobre temas trazidos pelos professores e estudantes timorenses que participam dos grupos. O grupo é coordenado por um professor brasileiro e um timorense, que ficam responsáveis pela proposição e coordenação dos temas a serem estudados e pesquisados pelo grupo. Os resultados das atividades do grupo são apresentados em eventos científicos, periódicos ou como capítulos de livro.

$\mathrm{Na}$ extensão, os cooperantes brasileiros desenvolvem cursos buscando suprir a necessidade de formação dos professores e estudantes da universidade, como, por exemplo, cursos de extensão sobre metodologia da pesquisa científica, educação ambiental, práticas pedagógicas etc.

$\mathrm{Na}$ gestão, as atividades de apoio são realizadas pelos articuladores pedagógicos do PQLP com o objetivo de compreender as necessidades da instituição, assim como de acompanhar e avaliar o trabalho desenvolvido entre os professores brasileiros e timorenses, buscando sempre, de modo compartilhado, a reflexão sobre (e a solução para) as dificuldades e os conflitos apresentados pelos professores brasileiros e pelos professores timorenses.

Quanto aos desafios e às contradições a serem superados no processo de construção de uma experiência de cooperação internacional compartilhada, a experiência prática e cotidiana, desenvolvida ao longo do ano de 2014, entre os profissionais da educação timorenses e os cooperantes brasileiros mostrou que são muitos e diversos. A título de ilustração podemos citar a problemática da complexidade linguística do país, da qual decorrem, por um lado, os problemas e dificuldades de aprendizagem da língua portuguesa pelos timorenses e, por outro, as dificuldades de ensino da língua ou em Língua Portuguesa pelos professores brasileiros. 
Embora a Língua Portuguesa tenha adquirido, formalmente, o estatuto de língua oficial e de ensino na legislação constitucional e educacional do país, na prática a realidade linguística é outra. Conforme vimos no primeiro item deste texto, Timor-Leste vive uma realidade multilíngue: são aproximadamente 16 línguas nativas faladas em seu território, entre as quais o tétum, que é a mais utilizada na capital do país e que também foi reconhecida como oficial pela legislação, ao lado da língua portuguesa. Além das línguas nativas, a língua indonésia também compõe esse quadro multilinguístico do país, pois de 1975, quando o território foi ocupado pelos indonésios, até 2002, a bahasa indonésia tornou-se a língua oficial e a língua portuguesa foi silenciada. Portanto, a geração mais velha, que viveu no período em que Timor-Leste era uma colônia portuguesa, é a única que ainda domina o português, porém hoje constitui a minoria da população. A geração que nasceu e viveu sob o domínio indonésio fala e compreende a língua indonésia, o tétum que é a língua franca, e uma das 16 línguas nativas faladas em sua família de origem que vive em diferentes regiões do interior do país.

Além dessas línguas, a língua inglesa também está presente no cotidiano timorense, talvez pela proximidade com a Austrália e, provavelmente, pela presença de estrangeiros falantes de inglês que chegaram com as cooperações internacionais desde que a ONU assumiu a administração transitória do país, em 1999. Essa complexidade linguística está presente dentro e fora das escolas timorenses, em todos os níveis de ensino. Sobre esse aspecto, temos que considerar, ainda, que Timor-Leste é uma nação jovem e tem uma cultura linguística marcada pela oralidade. Escrever sua história na língua oficial portuguesa, sem perder sua origem e identidade cultural, é um grande desafio e também uma contradição que se põe aos cidadãos timorenses.

Para os professores brasileiros que participam do PQLP e assumem a tarefa de ensinar a língua portuguesa ou em língua portuguesa nas escolas timorenses, essa contradição se revela assim que chegam ao país. Ao descer no aeroporto e andar pelas ruas da capital, constata-se a ausência da língua portuguesa, e não só quando se tenta falar com os timorenses, pois se pode notar essa ausência na sinalização e nas placas que compõem a paisagem linguística da cidade. Ou seja, todas as informações são escritas na língua tétum, na língua indonésia ou em inglês. Raramente se encontra uma informação escrita em língua portuguesa, o que revela, segundo alguns estudiosos da área, a ausência, na prática, de desenvolvimento e investimento de uma política linguística que seja coerente com a realidade e a legislação do país (DIAS, 2015).

Quando os professores brasileiros iniciam o trabalho de formação nas instituições timorenses, deparam-se com essa contradição em reuniões com os gestores e professores das instituições, nos 
corredores e nas salas de aulas das escolas. Ou seja, a comunicação entre brasileiros e timorenses se torna uma barreira, pois poucos nativos realmente entendem ou falam português, e os brasileiros não compreendem ou falam a língua tétum. Na universidade, por exemplo, em uma sala com aproximadamente 50 estudantes, convivem as diferentes línguas nativas e apenas alguns se comunicam bem em língua portuguesa. Essa é uma barreira que se impõe na relação de ensino e aprendizagem entre o professor brasileiro e os estudantes timorenses e que precisa ser superada.

Ao embarcarem nessa missão, os professores, selecionados pelo PQLP, participam de uma atividade de formação denominada pré-partida, cujo objetivo é prepará-los para o trabalho em solo timorense. No entanto, apenas o contato com a realidade pode lhes dar a exata dimensão da complexidade linguística do país. Esse é um dos aspectos que marca o movimento contraditório da realidade concreta timorense e que deve ser compreendido pelos timorenses e brasileiros que compartilham experiências e conhecimentos em educação. Compreender e reconhecer essa complexidade multilíngue pode contribuir para a construção da identidade cultural timorense e da identidade da cooperação educacional brasileira, representada pelo PQLP.

Interrupções das atividades da cooperação brasileira em solo timorense, provocadas por questões de ordem política e econômica no âmbito das relações de cooperação internacional entre os países, têm gerado a descontinuidade das ações desenvolvidas pelo PQLP. Esse também é um desafio que precisa ser superado, pois dele depende a continuidade e o fortalecimento do vínculo entre timorenses e brasileiros que participam da cooperação.

Registramos aqui alguns exemplos das atividades realizadas entre professores cooperantes do PQLP e professores timorenses, e também alguns desafios e contradições que a experiência cotidiana nos mostrou. No entanto, conforme já afirmamos, a realidade concreta revela o fenômeno apenas em sua aparência, pois para conhecê-lo em sua essência é preciso estudá-lo. Muitos desafios ainda precisam ser superados nesse processo de construção de uma cooperação internacional compartilhada que tem por princípio a aprendizagem por meio da troca de experiências e conhecimentos entre os países e os sujeitos participantes dessa cooperação.

A experiência acumulada pelo PQLP, nos últimos anos de atuação em Timor-Leste, tem mostrado que a construção da identidade de um programa de cooperação educacional compartilhada, entre o Brasil e Timor-Leste, é um processo permeado de contradições, desafios e possibilidades. No que se refere às possibilidades, como lembra Gramsci $(1978$, p. 47), “[ [...] a possibilidade não é a 
realidade, mas é também ela, uma realidade: que o homem possa ou não possa fazer determinada coisa, isto tem importância na valorização daquilo que realmente se faz". Ou seja, se existem

[...] as possibilidades objetivas de não morrer de fome e que, mesmo assim, se morra de fome, é algo importante, ao que parece. Mas a existência das condições objetivas ou possibilidade, ou liberdade - ainda não é suficiente: é necessário "conhecê-las" e saber utilizá-las. Querer utilizá-las. (GRAMSCI, 1978, p. 47).

Nossa experiência e nossas análises demonstraram que a possibilidade de construção de um programa de cooperação compartilhada já é uma realidade, mas precisamos estudá-la e conhecê-la para que possamos utilizá-la em favor do processo de construção da sua identidade.

Em síntese, esta reflexão, iniciada em reuniões de trabalho na Universidade Nacional TimorLorosa'e, nasceu, por um lado, da necessidade de compreender o movimento contraditório da realidade econômica, política, social, educacional e cultural timorense, e, por outro, da necessidade de refletir sobre os desafios e possibilidades de construção de uma experiência de cooperação educacional compartilhada, entre Brasil e Timor-Leste. Neste artigo, apresentamos uma síntese provisória dos resultados dos estudos preliminares que realizamos para construir nosso objeto e problemática de pesquisa, com base em questionamentos que se originaram no interior da nossa prática pedagógica em cooperação educacional em Timor-Leste. Esses estudos revelaram que há um longo caminho a ser percorrido para podermos responder aos nossos questionamentos. Portanto, essa primeira síntese será superada e novas serão objetivadas, daí o seu caráter provisório.

\section{Considerações finais}

A motivação para desenvolver o presente estudo nasceu da nossa experiência de trabalho ao longo do ano de 2014. As dificuldades e os desafios que enfrentamos no desenvolvimento de nossas atividades em solo timorense, bem como os resultados positivos dessa parceria, intensificaram nosso diálogo e geraram a necessidade de aprofundamento de nossas reflexões sobre a problemática que Timor-Leste vive atualmente: a contradição entre a necessidade de preservar a sua identidade cultural e, ao mesmo tempo, atender à agenda de compromissos assumidos com as agências de Cooperação Internacional para o Desenvolvimento, as quais chegaram ao país com o objetivo de ajudar na (re)construção do Estado-Nação timorense. 
Percebemos que os agentes da cooperação internacional, contratados como consultores e técnicos, especialistas em educação, por essas agências, chegam ao país para cumprir missões a partir de projetos pré-determinados pelas agências contratantes, os quais nem sempre atendem às necessidades locais. Nesse sentido, levam para o país concepções de mundo e experiências profissionais adquiridas em seus países de origem, as quais, muitas vezes, são conflitantes com os valores culturais locais.

Entre as características da cultura timorense, além daquelas multiculturais e linguísticas que citamos, destacamos a capacidade, desenvolvida por seu povo, de resistir aos ataques e desmandos impostos por nações estrangeiras ao longo do processo histórico de desenvolvimento do país. Do nosso ponto de vista, essa é uma característica cultural que se constitui em um princípio educativo, transmitido de geração em geração pela sociedade timorense. Com base nessa constatação, consideramos essa característica favorável à preservação da identidade cultural do país, a qual, embora venha sendo respeitada e alimentada por seus governantes, tem sido apropriada pelas agências internacionais de cooperação como estratégia destas para ocultar seus reais interesses e finalidades.

Os resultados preliminares deste estudo apontam para a necessidade de análises críticas que problematizem o momento histórico que o país enfrenta com a presença das agências da Cooperação Internacional para o Desenvolvimento. Portanto, avaliamos que pesquisar a atuação da Cooperação Internacional para o Desenvolvimento, buscando compreendê-la do ponto de vista das relações históricas e sociais que a constituíram é fundamental para responder às questões apresentadas no início deste artigo, bem como para a continuidade do desenvolvimento de uma cooperação educacional compartilhada entre o Brasil e Timor-Leste, de modo que possa contribuir para a produção do conhecimento e para a educação de ambos os países.

\section{Notas}

${ }^{1}$ Termo utilizado pelos timorenses para se referirem aos estrangeiros, ou não nativos (COSTA, 2000).

${ }^{2}$ Termo utilizado pelos timorenses para designar a população nativa (COSTA, 2000).

3 Por ti Timor, canção de autor desconhecido. Disponível em: <https://naraiz.wordpress.com/2013/04/07/por-ti-timor/>. Acesso em: 10 ago. 2015. 


\section{REFERÊNCIAS}

BOGO, Ademar. Identidade e luta de classes. 2. ed. São Paulo: Expressão Popular, 2010.

BORMANN, Aliete; SILVEIRA, Marília. Primeira missão de especialistas brasileiros em educação em Timor-Leste: desafios e impasses. In: SILVA, Kelly Cristiane da; DAMIÃO, Daniel (Org.). TimorLeste por trás do palco: cooperação internacional e a dialética da formação do Estado. Belo Horizonte: Editora da UFMG, 2007. p. 234 -254.

BRASIL. Decreto ${ }^{\circ}$ 5.104, de 11 de junho de 2004. Promulga o Acordo de Cooperação Educacional entre o Governo da República Federativa do Brasil e o Governo da República Democrática de TimorLeste, celebrado em Díli, em 20 de maio de 2002. Diário Oficial da União, Brasília, 14 jun. 2004a. Disponível em: <http://www2.camara.leg.br/legin/fed/decret/2004/decreto-5104-11-junho-2004532629-publicacaooriginal-14915-pe.html>. Acesso em: 25 ago. 2015.

BRASIL. Decreto $n^{0} 5.274$, de 18 de novembro de 2004. Institui o Programa de Qualificação de Docente e Ensino de Língua Portuguesa no Timor-Leste, e dá outras providencias. Diário Oficial da União, Brasília, DF, 19 nov. 2004b. Disponível em: <http://www2.camara.leg.br/legin/fed/decret/2004/decreto-5274-18-novembro-2004-534787-normape.html>. Acesso em: 25 ago. 2015.

BRASIL. Ministério das Relações Exteriores. Agência Brasileira de Cooperação. Manual de Gestão da Cooperação Técnica Sul-Sul. Brasília, DF: MRE, 2013. Disponível em:

<http://www.abc.gov.br/Content/ABC/docs/Manual_SulSul_v4.pdf>. Acesso em: 10 jun. 2015.

CAMPOS, Rodrigo Pires de. A cooperação técnica brasileira entre países em desenvolvimento: limites e perspectivas da política externa nacional. In: SILVA, Kelly Cristiane da; DAMIÃO, Daniel (Org.). Timor-Leste por trás do palco: cooperação internacional e a dialética da formação do Estado. Belo Horizonte: Editora da UFMG, 2007. p. 343-364.

COSTA, Luis. Dicionário de Tétum-Português. Lisboa: Colibri; Universidade de Letras de Lisboa, 2000.

DIAS, Christiane da Silva. “[...] é língua oficial de Timor-Leste, quer não quer nós tem falar”: reflexões sobre políticas e práticas linguísticas em Díli. 2015. 124 p. Dissertação (Mestrado em Linguística) - Universidade Federal de Santa Catarina, Florianópolis, 2015.

FREIRE, Paulo. Cartas à Guiné-Bissau: registros de uma experiência em processo. 2. ed. Rio de Janeiro: Paz e Terra, 1978. (O Mundo, hoje, v. 22). Disponível em:

<http://www.dhnet.org.br/direitos/militantes/paulofreire/paulo_freire_cartas_a_guine_bissau.pdf >. Acesso em: 10 jul. 2015.

FRIGOTTO, Gaudêncio. Educação e crise do capitalismo real. São Paulo: Cortez, 1995.

FIORI, José Luis. 60 lições dos 90: uma década de neoliberalismo. 2. ed. Rio de Janeiro: Record, 2002. 

possibilidades a partir da experiência compartilhada entre Brasil e Timor-Leste

GENTILI, Pablo. Neoliberalismo e educação: manual do usuário. In: SILVA, Tomaz Tadeu; GENTILI, Pablo (Org.). Escola S. A.: quem ganha e quem perde no mercado educacional do neoliberalismo. Brasília, DF: CNTE, 1996. p. 9-49.

GRAMSCI, Antonio. A concepção dialética da história. 3. ed. Rio de Janeiro: Civilização Brasileira, 1978.

GUEDES, Maria Denise. Educação de jovens e adultos: o debate na década de 1990. 2006. 139p. Tese (Doutorado em Educação) - Universidade Federal de São Carlos, São Carlos, 2006.

IGLESIAS PUENTE, Carlos Alfonso. A cooperação técnica horizontal brasileira como instrumento de política externa: a evolução da cooperação técnica com países em desenvolvimento - CTPD - no período 1995-2005. Brasília: FUNAG, 2010. Disponível em: <http://funag.gov.br/loja/download/715Cooperacao_Tecnica_Horizontal_Brasileira_como_Instrumento_da_PolItica_Externa_A.pdf $>$. Acesso em: 23 mar. 2016.

KOSIK, Karel. Dialética do concreto. Tradução de Célia Neves e Alderico Toríbio. 6. ed. Rio de Janeiro: Paz e Terra, 1995.

MARTINS, Francisco M. Autoavaliação institucional da educação superior: uma experiência brasileira e suas implicações para a educação superior de Timor-Leste. 2010. 302p. Tese (Doutorado em Educação) - Universidade Federal da Bahia, Salvador, 2010. Disponível em:

$<$ https://repositorio.ufba.br/ri/bitstream/ri/10188/1/Tese\%20_\%20Francisco\%20Martins\%20Seg.pdf>. Acesso em: 1 jun. 2014.

MARX, Karl. Para a crítica da economia política. In: MARX, Karl. Manuscritos econômico-filosóficos e outros textos escolhidos. Tradução de José Arthur Giannotti e Edgar Malagodi. 4. ed. São Paulo: Nova Cultural, 1987. v. 1. (Coleção Os Pensadores). p. 4-25.

MATTOSO, José. A dignidade: Konis Santana e a resistência timorense. 2. ed. Lisboa: Temas e Debates, 2012.

MILANI, Carlos R. S. Evolução histórica da cooperação Norte-Sul. In: SOUZA, André de M. (Org.). Repensando a cooperação internacional para o desenvolvimento. Brasília, DF: Ipea, 2014. Disponível em: <http://www.ipea.gov.br/portal/index.php?option=com_content\&view=article\&id=24257>. Acesso em: 10 jun. 2015.

NEVES, Guteriano Nicolau. O paradoxo da cooperação em Timor-Leste. Tradução de Cássia Bechara. In: SILVA, Kelly Cristiane da; DAMIÃO, Daniel (Org.). Timor-Leste por trás do palco: cooperação internacional e a dialética da formação do Estado. Belo Horizonte: Editora da UFMG, 2007. p. 97-121.

SALGADO, Maria Inez. Herança portuguesa na Ásia: Timor-Leste e seus desafios contemporâneos: educação e soberania. Revista Contemporânea de Educação, Rio de Janeiro, v. 1, n. 1, p. 01-09, dez. 2011. Disponível em: <http://revistas.ufrj.br/index.php/rce/article/view/1478>. Acesso em: 10 jul.2015. 
SILVA, Kelly Cristiane da. As nações desunidas: práticas da ONU e a estruturação do Estado em Timor-Leste. Belo Horizonte: Editora da UFMG, 2012.

SILVA, Maria Abádia da. Do projeto político do Banco Mundial ao projeto político-pedagógico da escola pública brasileira. Cadernos Cedes, Campinas, SP, v. 23, n. 61, p. 283-301, dez. 2003. Disponível em: <www.scielo.br/pdf/ccedes/v23n61/a03v2361.pdf>. Acesso em: 10 maio 2015.

SIMIÃO, Daniel S.; SILVA, Kelly Cristiane da. Timor-Leste por trás do palco, um prólogo. In: SILVA, Kelly Cristiane da; DAMIÃO, Daniel (Org.). Timor-Leste por trás do palco: cooperação internacional e a dialética da formação do Estado. Belo Horizonte: Editora da UFMG, 2007. p. 11-24.

THOMAZ, Luís Felipe. País dos belos: achegas para a compreensão de Timor-Leste. Lisboa: Fundação do Oriente, 2008. 

possibilidades a partir da experiência compartilhada entre Brasil e Timor-Leste

\section{International Cooperation for Development and Education: a preliminary study on the challenges and possibilities of a shared experience between Brazil and East Timor}

\begin{abstract}
The aim of this article is to systematize the results of preliminary studies on the challenges and possibilities of developing a shared international cooperation work in East Timor. In this sense, starting from the questioning of the role of International Cooperation for Development in developing countries, we have as an initial hypothesis that after the restoration of independence in 2002 and the arrival of international cooperation agencies, which arrived in East Timor in order to "help" in the construction of the nation state, the biggest challenge the country faces is confronting the contradiction between, on the one hand, meet the requirements of international agencies, captained by the United Nations (UN) and the World Bank, to put the Timorese State and its institutions in the tracks of "globalization" and, on the other hand, to hold and to preserve their cultural identity. Therefore, based on bibliographical studies, on the theoretical and methodological assumptions of Marxist dialectics and on the thought of Paulo Freire, as well as on the experience lived by the authors through the Teachers Training Program and Portuguese Language Teaching in East Timor, we conclude that commitment, political will and respect for cultural differences between those involved in cooperation actions are ingredients needed to overcome the challenges and move forward in building a shared international cooperation relationship.
\end{abstract}

Keywords: International Cooperation. Education Internationalization. Global Context.

Maria Denise Guedes

E-mail:mdgyuri@hotmail.com

Vicente Paulino

E-mail: vicentepaulino123@gmail.com
Coopération Internationale pour le Développement et l'Éducation: une étude préliminaire sur les défis et les possibilités d'une expérience partagée entre le Brésil et le Timor Est

\section{Résumé}

Cet article vise à systématiser les résultats des études préliminaires sur les défis et les possibilités de développement d'un travail de coopération internationale partagée au Timor Est. En ce sens, à partir de la problématisation du rôle de la Coopération Internationale pour le Développement dans les pays en développement, on a l'hypothèse initiale que, après la restauration de l'indépendance en 2002 et l'arrivée des organismes de coopération internationale, qui y sont arrivé pour «aider» à la construction de l'État-nation, le grand défi pour le Timor Est est la confrontation des contradictions entre, d'une part, de répondre aux exigences des organismes internationaux, gérés par les Nations Unies (ONU) et la Banque mondiale, de mettre l'État timorais et ses institutions dans les pistes de la "mondialisation" et, de l'autre, de défendre et de préserver leur identité culturelle. Donc, basé sur des études bibliographiques, des hypothèses théoriques et méthodologiques de la dialectique marxiste et la pensée de Paulo Freire, ainsi que dans l'expérience vécue par les auteurs à travers le Programme de qualification des enseignants et de l'enseignement des langues portugaise au Timor Est, on conclut que l'engagement, la volonté politique et le respect des différences culturelles entre les sujets impliqués dans des actions de coopération sont ingrédients nécessaires pour surmonter les défis et avancer dans la construction d'une relation de coopération internationale partagée.

Mots-clés: Coopération Internationale. Internationalisation de l'Éducation. Contexte Mondial.

Recebido em: $31 / 8 / 2015$

Aprovado em: 13/3/2016 